\title{
Nonlinear Fracture Mechanics investigation on the ductility of reinforced concrete beams
}

\section{Investigação sobre a ductilidade de vigas de concreto armado com base na Mecânica da Fratura Não-linear}
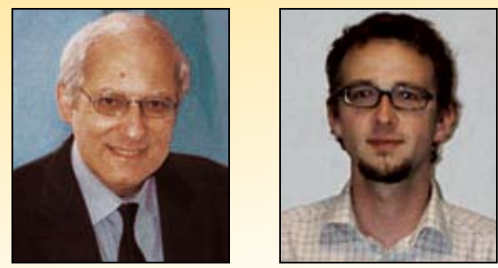

\author{
A. CARPINTERI \\ alberto.carpinteri@polito.it \\ M. CORRADO \\ mauro.corrado@polito.it
}

\begin{abstract}
In the present paper, a numerical algorithm based on the finite element method is proposed for the prediction of the mechanical response of reinforced concrete $(\mathrm{RC})$ beams under bending loading. The main novelty of such an approach is the introduction of the Overlapping Crack Model, based on nonlinear fracture mechanics concepts, to describe concrete crushing. According to this model, the concrete damage in compression is represented by means of a fictitious interpenetration. The larger is the interpenetration, the lower are the transferred forces across the damaged zone. The well-known Cohesive Crack Model in tension and an elastic-perfectly plastic stress versus crack opening displacement relationship describing the steel reinforcement behavior are also integrated into the numerical algorithm.

The application of the proposed Cohesive-Overlapping Crack Model to the assessment of the minimum reinforcement amount necessary to prevent unstable tensile crack propagation and to the evaluation of the rotational capacity of plastic hinges, permits to predict the size-scale effects evidenced by several experimental programs available in the literature. According to the obtained numerical results, new practical design formulae and diagrams are proposed for the improvement of the current code provisions which usually disregard the size effects.
\end{abstract}

Keywords: Nonlinear Fracture Mechanics, Reinforced concrete, Minimum reinforcement, Rotational capacity, Size effects, Codes provisions.

\begin{abstract}
Resumo
Neste artigo, um algoritmo numérico baseado no método dos elementos finitos é proposto para a predição da resposta mecânica de vigas de concreto armado carregadas em flexão. A principal novodade de tal abordagem é a introdução do modelo de superposição de fissuras, baseado em conceitos de mecânica da fratura não linear, para descrver o esmagamento do concreto. De acordo com esse modelo, o dano em compressão do concreto é representado por meio de uma interpenetração fictícia. Quanto maior a interpenetração, menores são as forças transferidas através da zona danificada. O conhecido Modelo de fissura coesiva em tração e uma relação tensão versus abertura da fissura elasto-perfeitamente plástica descrevendo o comportamento da armadura de aço são também integrados no algoritmo numérico.

A aplicação do Modelo de Fissura Coesiva superposta para a avaliação da armadura mínima necessária para prevenir propagação instável de fissura por tração e para a avaliação da capacidade rotacional de rótulas plásticas, permite prever efeito escala evidenciado por vários programas experimentais disponíveis na literatura. De acordo com os resultados númericos obtidos, novos fórmulas e diagramas para projeto são propostos para aprimoramento de normas atuais que usualmente desprezam efeito escala.
\end{abstract}

Palavras-chave: Mecânica da Fratura Não Linear, Concreto armado, capacidade rotacional, efeito escala, prescrições de normas.

a Politecnico di Torino, Department of Structural Engineering and Geotechnics, alberto.carpinteri@polito.it, Corso Duca degli Abruzzi 24, 10129, Torino, Italy

b Politecnico di Torino, Department of Structural Engineering and Geotechnics, mauro.corrado@polito.it, Corso Duca degli Abruzzi 24, 10129,

Torino, Italy 


\section{Introduction}

Reinforced concrete (RC) beams are usually designed to perform a ductile response under bending loadings. According to most codes of practice, such a requirement is considered to be satisfied when the lower and the upper limits to the steel ratio are observed. The reinforcement amount, in fact, has to be such as to prevent unstable crack propagation (curve $a$ in Figure 1) and to avoid brittle failure due to concrete crushing without steel yielding (curve $c$ in Figure 1). Within these limitations, the overall response is ductile (curve $b$ in Figure 1) and hence elastic analysis with moment redistribution or even plastic analysis can be applied to RC structures (Corley [1], Macchi [2,3]). Besides, the ductility, usually defined by means of the rotational capacity of plastic hinges, contributes to satisfy many other requirements, absolutely necessary in order to guarantee the structural safety, as, e.g., to give warning of incipient collapse by the development of large deformation prior to collapse and to enable major distortions and energy dissipation during earthquakes. Nevertheless, the main drawback is that the practical prescriptions provided by design codes for the minimum reinforcement amount completely disregard the size-scale effects, leading to unsafe design conditions (small structures) or to a waste of materials (large structures). Analogous remarks also hold for the rotational capacity provisions, which over-estimate the ductility of deep beams.

\subsection{Minimum reinforcement in design codes}

Limit Analysis of RC beams usually assumes that stretched concrete is not bearing load and so the cracking phenomenon is not taken into account in the evaluation of the load carrying capacity. This assumption not always yields to a safe design condition, as for instance in the case of lightly reinforced concrete beams, where the tensile concrete contribution determines a hyper-strength with respect to the ultimate loading condition, and a consequent possible instability in the overall mechanical response. In this case, in fact, the resistant bending moment after the peak cracking moment is a monotonic decreasing function of the crack length, due to an unstable fracture propagation. For this reason, all national and international codes of practice provide empirical formulas for the determination of the minimum reinforcement amount which enable $\mathrm{RC}$ members to prevent unstable crack propagation. Most of them consider only two parameters: the concrete grade and the steel yield strength, whereas other important parameters, such as the beam depth, are completely neglected. A collection of several practical relationships is reported in Figure 2, where the values of minimum reinforcement, $\rho_{\min }$, are reported as functions of the beam depth, $h$, for a concrete compressive strength $\sigma_{c}=40 \mathrm{MPa}$, and a steel yielding strength $\sigma_{\mathrm{y}}=400 \mathrm{MPa}$. It can be seen that only the Norwegian Standards NS $3473 \mathrm{E}$ [4] account for the effect of the member size, by means of the size-effect factor, $k_{w}$, equal to $1.5-h / h_{1} \geq 1$, where $h$ is the beam depth in $\mathrm{m}$, and $h_{1}$ is equal to $1 \mathrm{~m}$. As a result, $\rho_{\min }$ is a linear decreasing function of the beam depth up to $0.5 \mathrm{~m}$, whereas it is assumed to be constant for higher values of $h$.

\subsection{Plastic rotation in design codes}

The current prescriptions provided by Model Code 90 [5] and Eurocode 2 [6] come from the experimental program coordinated by the "Indeterminate Structures Commission" of the Comité Européen

\section{Figure 1 - Conditions for structural design of reinforced concrete members with ductile response}

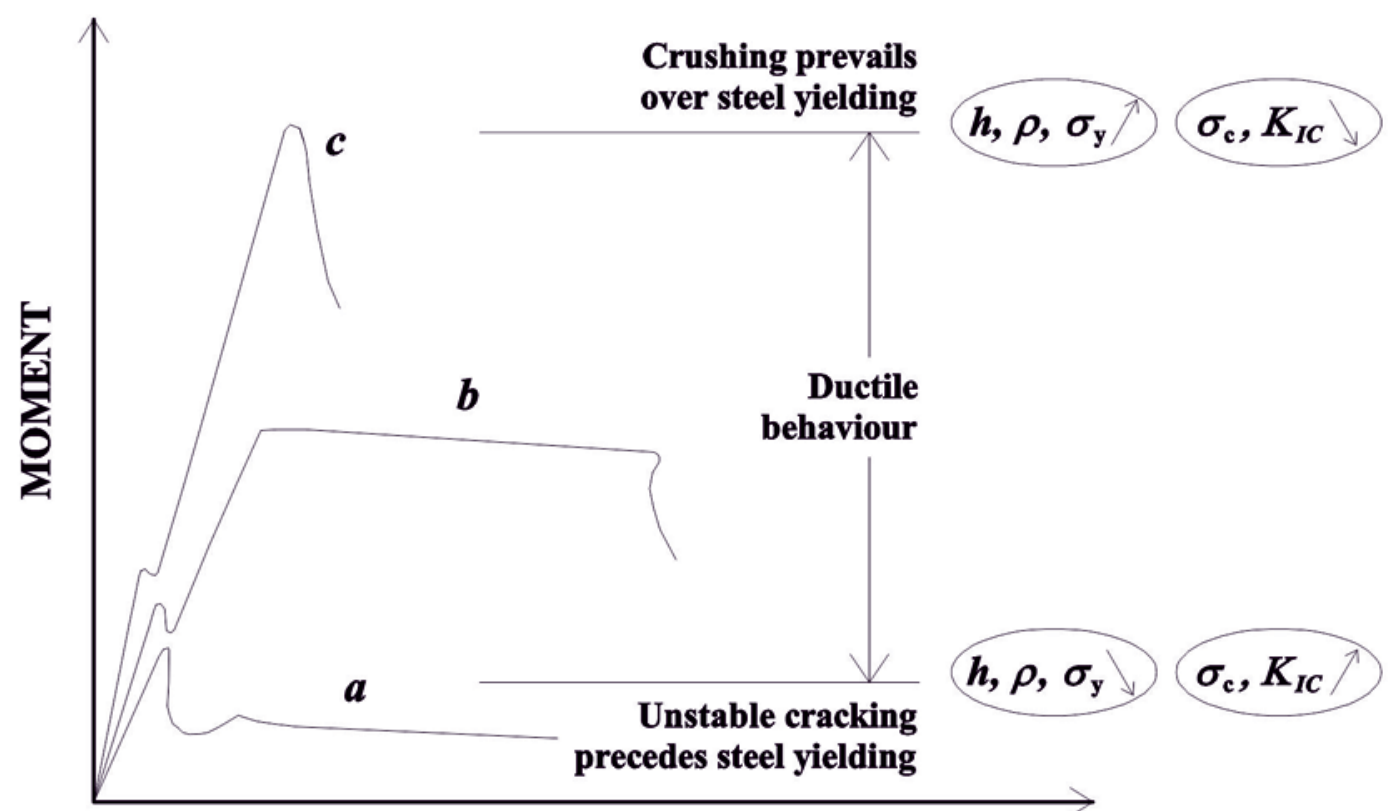

ROTATION 
Figure 2 - Minimum reinforcement amount vs. beam depth according to various design codes

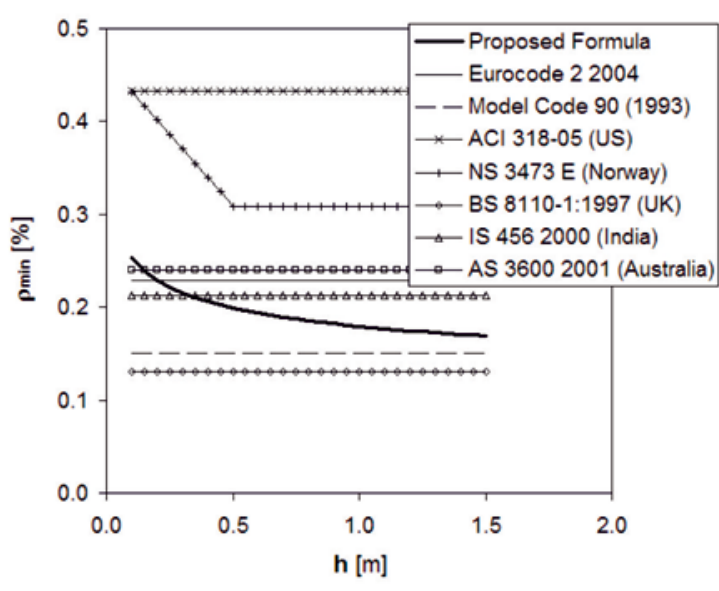

du Béton [7] in the 1960s and from the research carried out in the early 1980 s at the University of Stuttgart by the group coordinated by Professor Eligehausen (Eligehausen; Langer [8]. In the latter study an analytical model was developed in order to describe the behavior of plastic hinges, considering that the final collapse can be achieved either by steel rupture or by concrete crushing. The diagram provided by Eurocode 2 for assessing the admissible rotational capacity of $\mathrm{RC}$ beams as a function of the relative neutral axis position, $x / d$, is shown in Figure 3 . The dashed lines refer to high ductility steel, while the solid ones refer to normal ductility steel. In the case of a step-by-step plastic structural analysis, the designer has to verify that the rotation required for the moment redistribution is lower than the admissible one. To this aim, for a given value of $x / d$ obtained from the application of the ultimate state analysis, he enters Figure 3 and determines the admissible plastic rotation as a function of the concrete grade. It has to be

\section{Figure 3 - Plastic rotation vs. relative neutral axis position relationships by Eurocode 2 (6)}

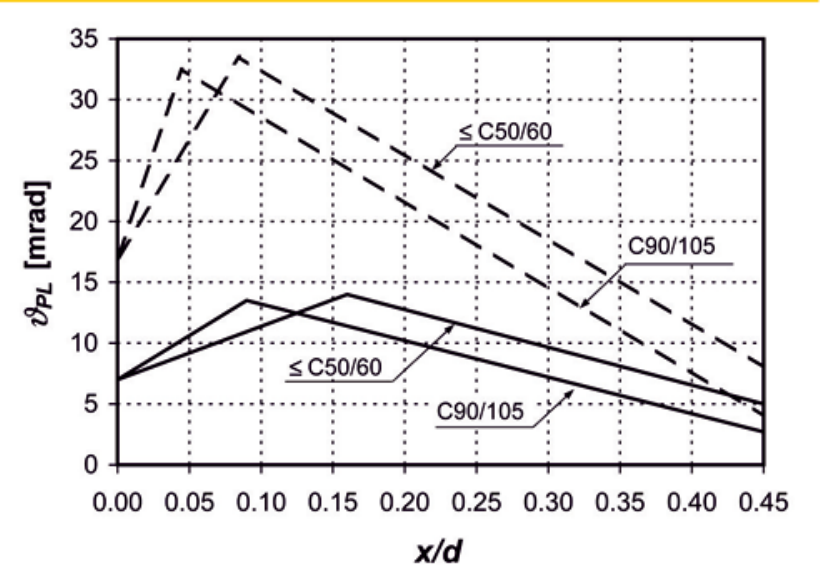

\section{Figure 4-Admissible moment redistribution vs. coefficient of resistance diagram by $\mathrm{ACl}$ Building Code (11)}

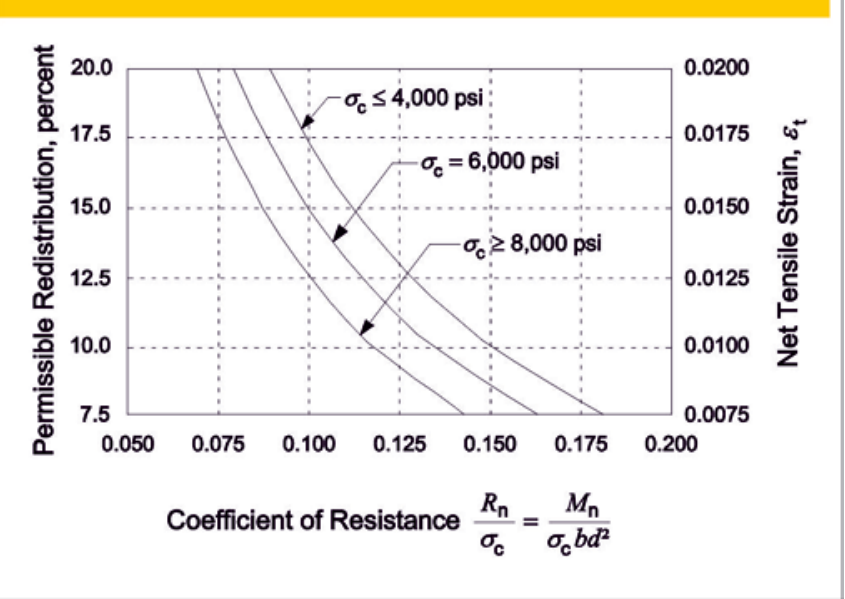

noted that the size-scale effects are not considered, although the dependence of the plastic rotation capacity on the structural dimension was recognized in several experimental tests (Corley [1], Bigaj; Walraven [9], Bosco; Debernardi [10]).

A different approach is proposed in the $\mathrm{ACl} 318$ Building Code [11] for the linear elastic analysis with moment redistribution procedure. In this case, the evaluation of the plastic rotation required by the plastic hinges is avoided by limiting the percentage of moment redistribution. Such a limit can be obtained by entering the diagram in Figure 4 with the coefficient of resistance, $M_{n} /\left(\sigma_{c} b d^{2}\right)-M_{n}$ is the nominal moment strength, $\sigma_{\mathrm{c}}$ is the concrete compressive strength, $b$ and $d$ are the thickness and the effective depth of the crosssection- for a given concrete compressive strength. Such curves have been selected in order to be the most conservative ones with respect to the beam slenderness and to the steel yielding strength (Mast [12]). Therefore, as a main difference with respect to the European approach, the $\mathrm{ACl}$ prescription introduces a safety factor for the admissible moment redistribution.

From the modeling point of view, the assessment of the minimum reinforcement amount and of the available ductility in RC beams is difficult to be achieved due to the simultaneous presence of different nonlinear contributions: crack opening in tension, concrete crushing in compression, and steel yielding or slippage. On the other hand, oversimplifications, based on the hypotheses usually assumed for the evaluation of the structural resistance, as, e.g., to neglect the concrete contribution in tension and to describe the nonlinear behavior of concrete in compression and steel in tension by means of $\sigma-\varepsilon$ constitutive laws, do not permit to model all the experimentally observed effects on the ductility of RC beams in bending. In particular, it is impossible to catch the size-scale effects, because the aforementioned constitutive laws consider only an energy dissipation within the volume in the nonlinear regime. In this context, two significant contributions have to be highlighted: the well-known Cohesive Crack Model proposed by Hillerborg et al. in 1976 [13] for concrete in tension, and the pioneering paper by Hillerborg in 1990 [14], who extended the concept of strain localization also in compression. 
In the present paper, the main features of a numerical method recently developed by Carpinteri et al. [15-17] able to describe the nonlinear behavior of RC members during both fracturing and crushing is briefly outlined. In particular, it will be shown that the crushing process can be efficiently analyzed according to the Overlapping Crack Model (Carpinteri et al. [18]), which considers a fictitious material interpenetration in the post-peak regime. With the proposed algorithm implemented in the finite element method, it is possible to completely capture the moment vs. rotation response of several experimental tests available in the literature. As a result of a parametric investigation, we first determine a new relationship for the minimum reinforcement amount, which is affected by sizescale effects. We will show that the codes prescriptions are not conservative in the case of small structural sizes, whereas they over-estimate the minimum amount in the case of large structural sizes. Then, plastic rotation vs. neutral axis position curves will be determined, that are found to be dependent on the structural dimension and the steel percentage. Finally, the percentage of moment redistribution vs. coefficient of resistance diagrams will be computed and directly compared with the $\mathrm{ACl}$ Building Code prescriptions. In this case, it will be shown that the European and the $\mathrm{ACl}$ prescriptions lead to over-estimate the rotational capacity of large beams.

\section{Numerical approach}

In this section, the numerical algorithm proposed by Carpinteri et al. [15-17] for the analysis of the mechanical behavior of a portion of a RC beam subjected to a constant bending moment, $M$, is briefly described. This element, having a span to depth ratio equal to unity, is representative of the zone of a beam where a plastic hinge formation takes place. It is assumed that fracturing and crushing processes are fully localized along the mid-span cross-section of the element. This assumption, fully consistent with the physics of the crushing phenomenon, also implies that only one equivalent main tensile crack is considered. The loading process is characterized by crack propagation in tension, steel yielding and/or slippage as well as concrete crushing in compression.

\subsection{Constitutive models}

In the proposed algorithm, the behavior of concrete in tension is described by means of the well established Cohesive Crack Model (Hillerborg et al. [13]), largely used, in the past, to study the ductileto-brittle transition in plain concrete beams in bending (Carpinteri $[19,20])$. According to this model, the adopted constitutive law is a stress-strain linear-elastic relationship up to the achievement of the tensile strength, $\sigma_{u}$, for the undamaged zone, and a stress-displacement relationship describing the process zone up to the critical opening, $w_{c r}^{t}$, is reached. The softening function, $\sigma$ $=f(w)$, is considered as a material property, as well as the critical value of the crack opening, $w_{c r}^{t}$, and the fracture energy, $G_{F}$. The shape of $f(w)$ may vary from linear to bilinear or even more complicated relationships depending on the characteristics of the considered material and the analyzed problem. The critical value of the crack opening displacement is approximately equal to 0.1 $\mathrm{mm}$, and the fracture energy is assumed to vary from $0.050 \mathrm{~N} / \mathrm{mm}$ to $0.150 \mathrm{~N} / \mathrm{mm}$, depending on concrete strength and maximum aggregate diameter, according to the prescriptions given by the Model Code 90 [5].
As far as modeling of concrete crushing failure is concerned, the Overlapping Crack Model introduced by Carpinteri et al. [18] is adopted. According to such an approach, strongly confirmed by experimental results (van Mier [21], Jansen; Shah [22]), and derived from the pioneering work by Hillerborg [14], the inelastic deformation in the post-peak regime is described by a fictitious interpenetration of the material, while the remaining part of the specimen undergoes an elastic unloading. As a result, a pair of constitutive laws for concrete in compression is introduced, in close analogy with the Cohesive Crack Model: a stress-strain relationship until the compression strength is achieved (Figure 5a), and a stress-displacement (overlapping) relationship describing the phenomenon of concrete crushing (Figure 5b). The latter law, approximated by a linear softening relationship for modeling purposes [18], describes how the stress in the damaged material decreases from its maximum value as the fictitious interpenetration increases. It is worth noting that the crushing energy, $G_{c}$, which is a dissipated surface energy, is defined as the area below the post-peak softening curve in Figure $5 \mathrm{~b}$. It can be assumed as a true material property, since it is not affected by the structural size, as shown by Carpinteri et al. [18] in case of plain or fiber reinforced concretes. The following empirical equation to calculate the crushing energy has been recently proposed by Suzuki et al. [23], taking into account the lateral confinement exerted by stirrups:

$$
G_{\mathrm{C}}=G_{\mathrm{C}, 0}+10000 \frac{k_{\mathrm{a}}^{2} p_{\mathrm{e}}}{\sigma_{\mathrm{c}}}
$$

where $\sigma_{c}$ is the average concrete compressive strength, $k_{\mathrm{a}}$ is a parameter depending on the stirrups strength and volumetric percentage, and $p_{\mathrm{e}}$ is the effective lateral pressure (see [23] for more details). The crushing energy for unconfined concrete, $G_{C, 0}$, can be calculated as follows:

$$
G_{\mathrm{C}, 0}=80-50 k_{\mathrm{b}}
$$

\section{where}

$$
k_{\mathrm{b}}=\frac{40}{\sigma_{\mathrm{c}}} \leq 1.0
$$

According to Eq. (2), the crushing energy ranges from 30 to $58 \mathrm{~N} /$ $\mathrm{mm}$, for concrete compressive strength varying from 20 to $90 \mathrm{MPa}$. The critical value for the crushing interpenetration is experimentally found to be approximately equal to $1 \mathrm{~mm}$ (see also Jansen; Shah [22]). Such a value is a decreasing function of the compressive strength, and an increasing function of concrete confinement.

As far as the behavior of steel reinforcement is concerned, it is impossible to adopt the classical $\sigma-\varepsilon$ laws, since the kinematics of the mid-span cross-section of the reinforced concrete member is described by means of displacements, instead of strains. To this aim, constitutive relationships between the reinforcement reaction 


\section{Figure 5 - Overlapping Crack Model for concrete in compression: linear-elastic law (a); post-peak softening $w$ relationship (b)}

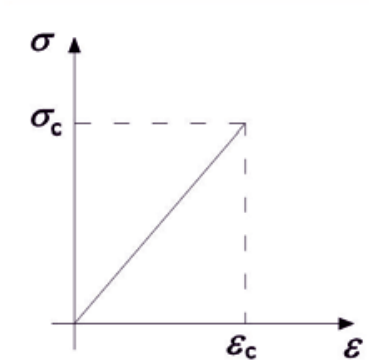

(a)

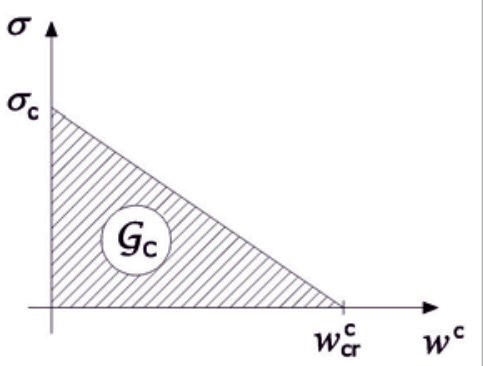

(b) and the crack opening displacement are obtained by means of preliminary studies carried out on the interaction between the reinforcing bar and the surrounding concrete. In particular, the integration of the differential slips over the transfer length, $I_{\text {tr }}$, is equal to half the crack opening at the reinforcement level, whereas the integration of the bond stresses gives the reinforcement reaction. Simplified procedure of such an approach have been proposed by Ruiz et al. [24]. Typically, the obtained relationships are characterized by an ascending branch up to steel yielding, to which correspond the critical value of the crack opening for steel, $w_{y}$. After that, the steel reaction is nearly constant.

\subsection{Numerical algorithm}

The reinforced concrete member is considered as constituted by two symmetrical elements characterized by an elastic behavior, and connected by means of $n$ pairs of nodes (Figure 6a). In this approach, all the mechanical nonlinearities are localized in the mid-span cross-section, where cohesive and overlapping stresses are replaced by equivalent nodal forces, $F_{\mathrm{i}}$, by integrating the corresponding stresses over the nodal spacing. Such nodal forces depend on the nodal opening or closing displacements according to the cohesive or overlapping softening laws previously introduced. With reference to Figure $6 \mathrm{a}$, the horizontal forces, $F_{\mathrm{i}}$, acting at the i-th node along the mid-span cross-section can be computed as follows:

$$
\{F\}=\left[K_{w}\right]\{w\}+\left\{K_{M}\right\} M
$$

where: $\{F\}$ is the vector of nodal forces, $\left[K_{w}\right]$ is the matrix of the coefficients of influence for the nodal displacements, $\{w\}$ is the vector of nodal displacements, $\left\{K_{M}\right\}$ is the vector of the coefficients of influence for the applied moment $M$.

Equation (4) constitutes a linear algebraic system of $n$ equations and $(2 n+1)$ unknowns, $\{F\},\{w\}$ and $M$. With reference to the generic situation reported in Figure $6 \mathrm{~b}, n$ additional equations can be introduced by considering the constitutive laws for concrete in tension and compression and for the reinforcement in the node $r$ (see Carpinteri et al. [15-17] for more details). The last additional equation derives from the strength criterion adopted to govern the propagation processes. At each step of the loading process, in fact, we can set either the force in the fictitious crack tip, $m$, equal to the ultimate tensile force, $F_{u}$, or the force in the fictitious crushing tip, $p$, equal to the ultimate compressive force, $F_{c}$. It is important to note that the condition for crack propagation (corresponding to the achievement of the tensile strength at the fictitious crack tip, $m$ ) does not imply that the compressive strength is reached at the corresponding overlapping crack tip, $p$, and viceversa. Hence, the driving parameter of the process is the tip that in the considered step has reached the limit resistance. Only this tip is moved when passing to the next step. This criterion will ensure the uniqueness of the solution on the basis of physical arguments. Finally, at

Figure 6 - Finite element nodes (a); and force distribution with cohesive crack in tension and crushing in compression (b) along the mid-span cross-section
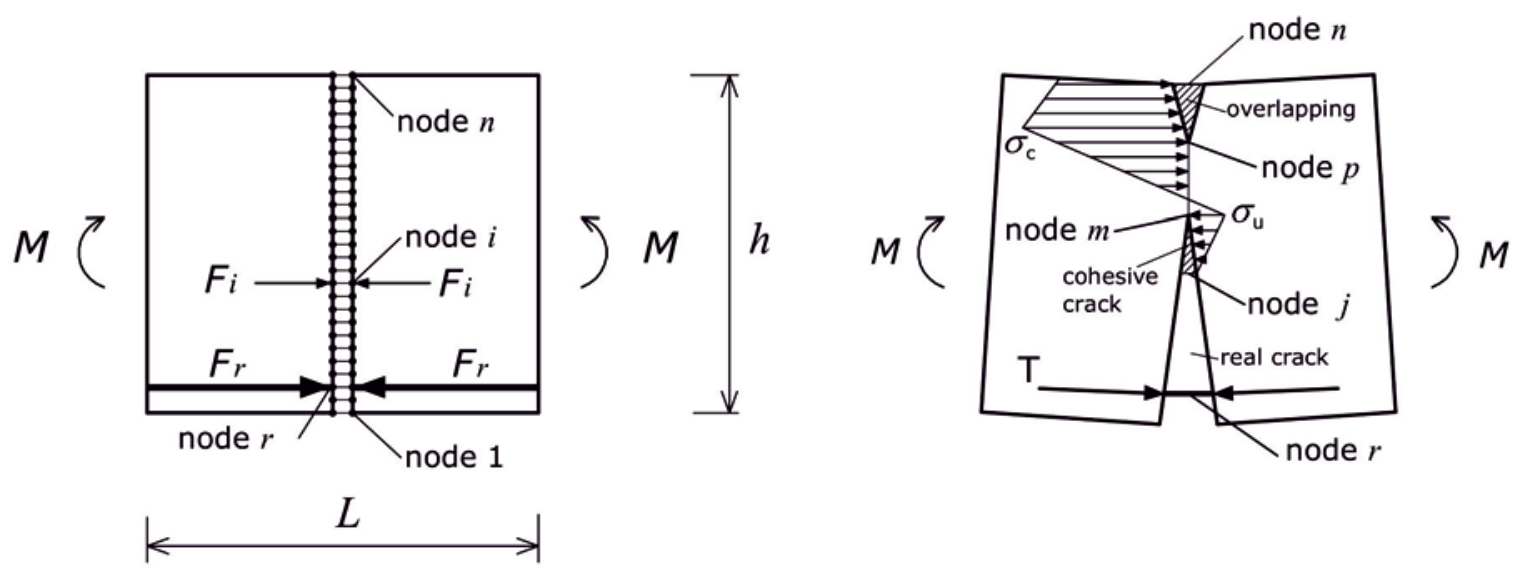
each step of the algorithm, it is possible to calculate the localized rotation, $\vartheta$, as follows:

$$
\vartheta=\left\{D_{w}\right\}^{T}\{w\}+D_{M} M
$$

where $\left\{D_{w}\right\}$ is the vector of the coefficients of influence for the nodal displacements and $D_{M}$ is the coefficient of influence for the applied moment. It is worth noting that Eqs. (4) and (5) permit to analyze the fracturing and crushing processes of the mid-span crosssection taking into account the elastic behavior of the reinforced concrete member. To this aim, all the coefficients are computed a priori using a finite element analysis.

\section{Comparison of numerical predictions and experimental results}

In this section, a comparison between the numerical predictions using the Cohesive/Overlapping Crack Model and the results of two experimental programs is presented. First, the three-point-bending tests carried out by Bosco et al. [25] on reinforced high-strength concrete beams to investigate the size-scale effects on the minimum reinforcement amount are considered. Three different size-scales were analyzed, characterized by a depth, $h$, equal to $0.1,0.2$ and $0.4 \mathrm{~m}$, and a constant thickness, $b$, equal to $0.15 \mathrm{~m}$. The span to depth ratio was equal to 6 . Five different steel percentages, $\rho$, were considered for each beam size. The concrete and the steel properties can be easily deduced from reference [25]. In the numerical simulations the RC element of Figure $6 a$ is assumed to be representative of the mid-span portion of the beam subjected to threepoint-bending test. As a result, the mid-span deflection is obtained as the sum of the contribution due to the localized rotation given by Eq. (5) and the elastic contribution, according to the following expression:

$$
\delta=\delta_{l o c}+\delta_{e l}=\frac{\vartheta L}{4}+\frac{1}{48} \frac{P L^{3}}{E_{c} I}
$$

where $L$ is the beam span, $P$ is the applied load, $E_{c}$ is the concrete elastic modulus, and $I$ is the moment of inertia of the cross-section.

Some of the numerical simulations compared to the corresponding experimental results, in terms of applied load vs. mid-span deflection curves, are shown in Figures 7 to 9 . Such curves evidence a transition from an overall softening response to a hardening response by increasing the steel percentage. Furthermore, it is worth noting that the condition for which the peak-cracking load is equal to the ultimate load occurs for values of reinforcement amount decreasing with the beam size (curves b in Figures 7 to 9). Such a phenomenon evidences a size-scale effect. A general good agreement is obtained between numerical and experimental results. Aiming at a further validation of the proposed model in the case of high steel percentages, the experimental analysis carried out by Bosco and Debernardi [10] on RC beams to investigate the size-scale effects on the rotational capacity is also considered. In order to obtain a consistent comparison, the numerical simulations have been carried out by modeling the beam portion positioned at the mid-span of the beam. This element is characterized by a span to depth ratio equal to one. The rotations of such a portion, where the largest amount of ductility is developed, were experimentally determined as functions of the applied bending moment. The mechanical and geometrical parameters are set equal to the experimental values. Numerical and experimental moment-rotation curves are compared in Figure $10 \mathrm{a}-\mathrm{c}$ for different beam depths and different steel percentages. Such diagrams put into evidence that the maximum rotation is a decreasing function of the tensile reinforcement ratio and of the beam depth. In the case of low steel percentages, the mechanical behavior is characterized by the reinforcement yielding and the mechanical response is almost plastic. By increasing the reinforcement amount, the contribution of concrete crushing becomes more and more evident with the appearance of a softening branch at the end of the plastic plateau. This is an important feature of the proposed model, which also permits to follow unstable softening branches with positive slopes (snap-back) by controlling the loading process through the length of the tensile crack and the extension of the fictitious crushing zone, rather than by the external load or the central deflection. Good agree-

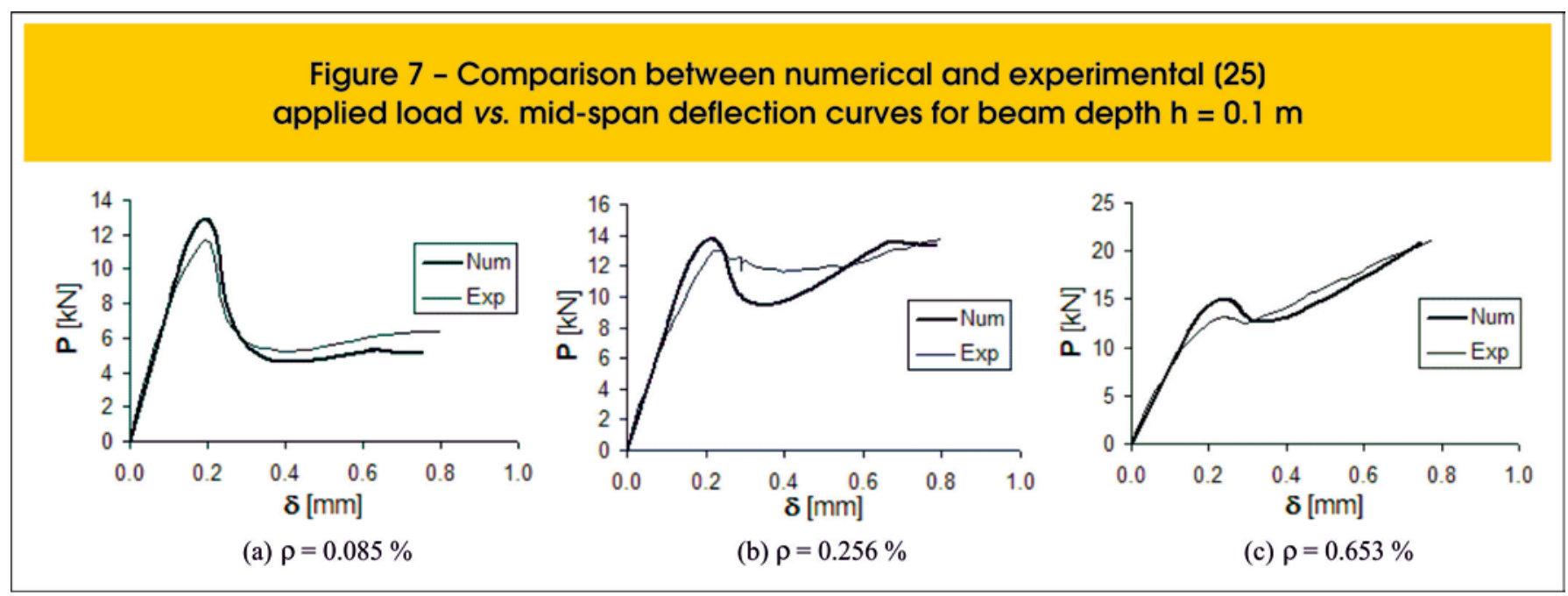


ment was obtained between numerical and experimental results for all the tested beams.

\section{Numerical results and new proposals for codes improvement}

\subsection{Minimum reinforcement}

In this section, a new relationship between the minimum reinforcement and the mechanical and geometrical parameters is proposed on the basis of a wide parametric analysis. To this aim, four different values of the beam depth, $h=0.1,0.2,0.4$ and $0.8 \mathrm{~m}$, and five different values of the concrete grade, $\sigma_{c}=$ $16,30,40,65$, and $76 \mathrm{MPa}$, have been considered. All the other mechanical properties of concrete, as, for instance, the tensile strength and the fracture energy, have been evaluated according to the relationships provided by the Model Code 90 [5]. As regards the steel reinforcement, a yield strength $\sigma_{y}=600 \mathrm{MPa}$, and an elastic modulus $E_{\mathrm{s}}=200 \mathrm{GPa}$ have been assumed. For each of the considered beams, several simulations have been carried out by varying the steel percentage, in order to find the minimum reinforcement amount. In particular, such a value is determined when the peak cracking load, $P_{\mathrm{cr}}$, is equal to the ultimate load, $P_{u}$, as shown in Figure 11 a.

When the flexural behavior of lightly RC beams is studied, according to the numerical model proposed in the previous section, the functional relationship among the quantities that characterize the phenomenon is the following:

$$
\mathrm{M}=\Phi\left(\sigma_{\mathrm{u}}, G_{\mathrm{F}}, E_{\mathrm{c}}, \sigma_{\mathrm{y}}, \rho, h ; \vartheta\right)
$$

where the parameters describing the behavior of concrete in compression, $\sigma_{c}$ and $G_{c}$, are not explicitly considered, since the crushing failure is not involved in the failure mechanism. On the other hand, only the beam depth, $h$, is considered if the geometrical ratios of the samples, $b / h$ and $L / h$, are assumed to be constant. The application of Buckingham's $\Pi$-Theorem (Buckingham [26]) for physical similarity and scale modeling permits to further minimize the dimension space of the pri-

\section{Figure 8 - Comparison between numerical and experimental (25) applied load vs. mid-span deflection curves for beam depth $\mathrm{h}=0.2 \mathrm{~m}$}

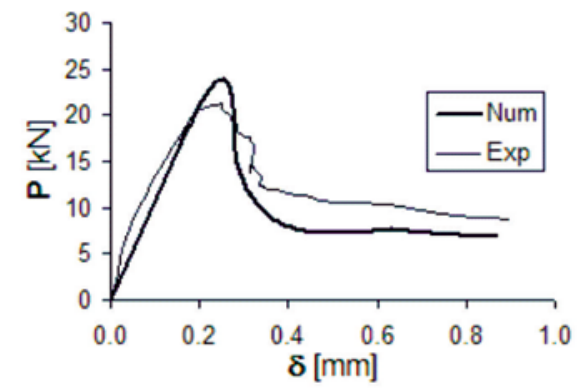

(a) $\rho=0.064 \%$

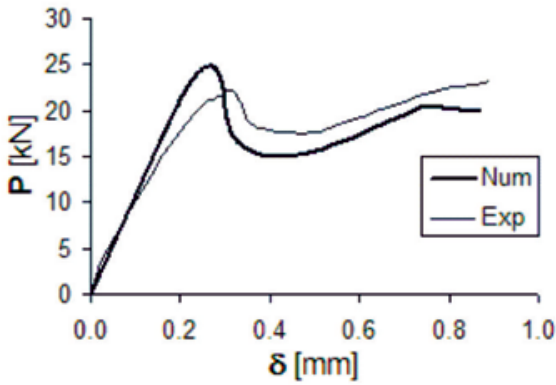

(b) $\rho=0.190 \%$

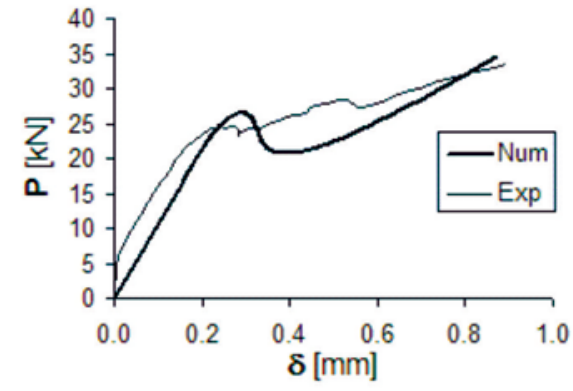

(c) $\rho=0.490 \%$

\section{Figure 9 - Comparison between numerical and experimental (25) applied load $v s$. mid-span deflection curves for beam depth $\mathrm{h}=0.4 \mathrm{~m}$}

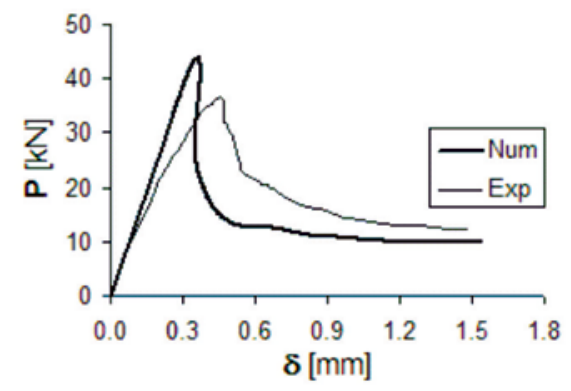

(a) $\rho=0.043 \%$

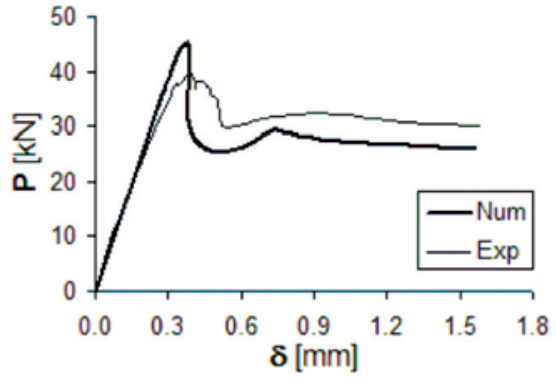

(b) $\rho=0.128 \%$

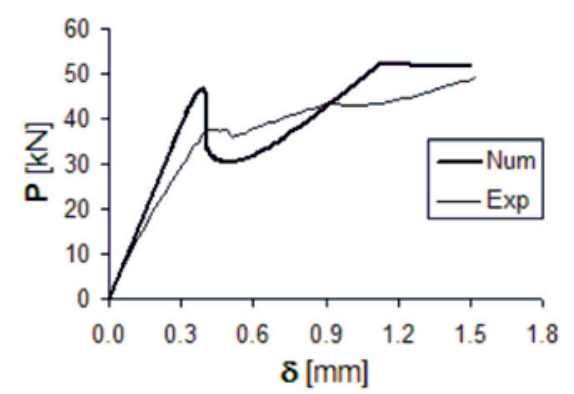

(c) $\rho=0.327 \%$ 


\section{Figure 10 - Comparison between numerical and experimental results (10) for different beam depths: $h=0.2 \mathrm{~m}(\mathrm{a}) ; \mathrm{h}=0.4 \mathrm{~m}(\mathrm{~b}) ; \mathrm{h}=0.6 \mathrm{~m}$ (c)}

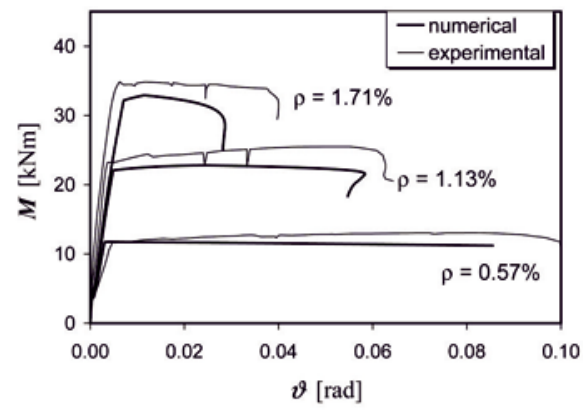

(a) $h=0.2 \mathrm{~m}$

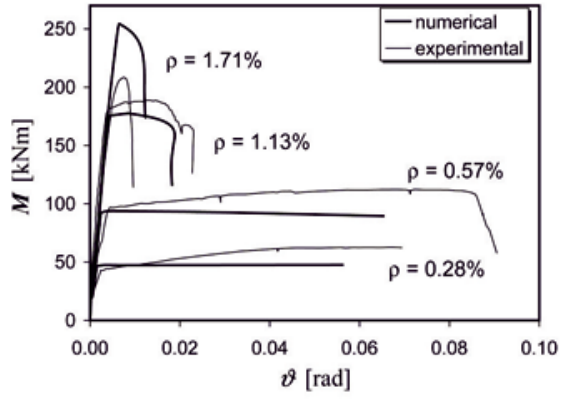

(b) $h=0.4 \mathrm{~m}$

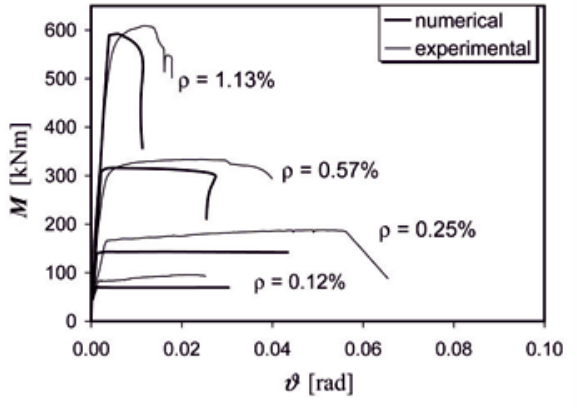

(c) $h=0.6 \mathrm{~m}$ mary variables by combining them into dimensionless groups, as follows:

$$
\frac{M}{h^{5 / 2} \sqrt{G_{\mathrm{F}} E_{\mathrm{c}}}}=\Phi_{1}\left(\frac{\sigma_{\mathrm{u}} h^{1 / 2}}{\sqrt{G_{\mathrm{F}} E_{\mathrm{c}}}}, \rho \frac{\sigma_{\mathrm{y}} h^{1 / 2}}{\sqrt{G_{\mathrm{F}} E_{\mathrm{c}}}}, \vartheta \frac{E_{\mathrm{c}} h^{1 / 2}}{\sqrt{G_{\mathrm{F}} E_{\mathrm{c}}}}\right)
$$

if $h$ and $\sqrt{\mathrm{G}_{\mathrm{F}} E_{\mathrm{c}}}$ are assumed as the dimensionally independent variables. It is worth noting that the term $\sqrt{\mathrm{G}_{\mathrm{F}} E_{\mathrm{c}}}$ corresponds to the concrete fracture toughness, $K_{I C}$. As a consequence, the dimensionless functional relation for the proposed model becomes:

$$
\widetilde{M}=\Phi_{2}\left(s, N_{P}, \vartheta_{n}\right)
$$

where:

$s=\frac{K_{I C}}{\sigma_{\mathrm{u}} h^{1 / 2}}$

and

$$
N_{P}=\rho \frac{\sigma_{\mathrm{y}} h^{1 / 2}}{K_{I C}}
$$

are the governing nondimensional numbers, $\tilde{M}$ is the nondimensional bending moment, and $\vartheta_{n}$ is the normalized local rotation. Equations (10) and (11) define the stress and the reinforcement brittleness numbers, introduced by Carpinteri in [27], [28], [29]. As a result, each numerical simulation is completely described by a different couple of values $s$ and $N_{P}$. In particular, the value of $N_{P}$ relative to the condition of minimum reinforcement is referred to as $N_{P C}$.
The values of $s$ and $N_{P C}$ for the numerical simulations carried out are shown in Figure 11b. Within the range considered for the input parameters, the obtained trend can be described with a very good approximation (goodness of fir $\mathrm{r} 2=0.999$ ) by the following hyperbolic curve:

$$
N_{P C}=0.26 s^{-0.71}
$$

By substituting Eqs. (10) and (11) into (12), the following relationship between the minimum reinforcement and the mechanical and geometrical properties of the beam is obtained:

$$
\rho_{\min }=0.26\left(\frac{\sigma_{\mathrm{u}} h^{0.5}}{K_{I C}}\right)^{0.71} \frac{K_{I C}}{\sigma_{\mathrm{y}} h^{0.5}}=0.26 \frac{\sigma_{\mathrm{u}}^{0.71} K_{I C}^{0.29}}{\sigma_{\mathrm{y}} h^{0.15}}
$$

According to Eq. (13), $\rho_{\min }$ is an increasing function of the concrete tensile strength and toughness, whereas it is a decreasing function of the steel yielding strength and of the beam depth. Such a relationship can be further rearranged for practical purposes, by expressing $\sigma_{u}$ and $K_{1 C}$ as functions of the concrete compressive strength, by means of the relationships provided by the Model Code 90, as follows:

$$
\rho_{\min }=0.2 \frac{\left(f_{\mathrm{ck}}+8\right)^{0.15} f_{\mathrm{ck}}^{0.47}}{\sigma_{\mathrm{y}} h^{0.15}}
$$

where $f_{c k}$ is the characteristic concrete compressive strength.

The new proposed formula is compared to the prescriptions of the design codes in Figure 2.

\subsection{Plastic rotation capacity}

A second detailed numerical study has been carried out to analyze the effect of the beam size and the steel percentage on the plastic rotation capacity. The following mechanical parameters have been assumed for 
Figure 11 - Definition of minimum reinforcement (a); and best-fit relationship of numerical results (not filled-in symbols) between NPC and s. Filled-in symbols refer to experimental results (25)

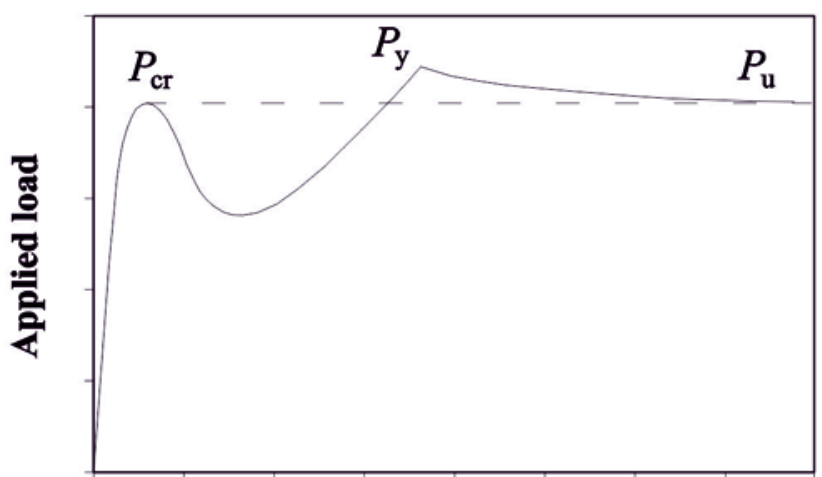

Mid-span deflection

(a)

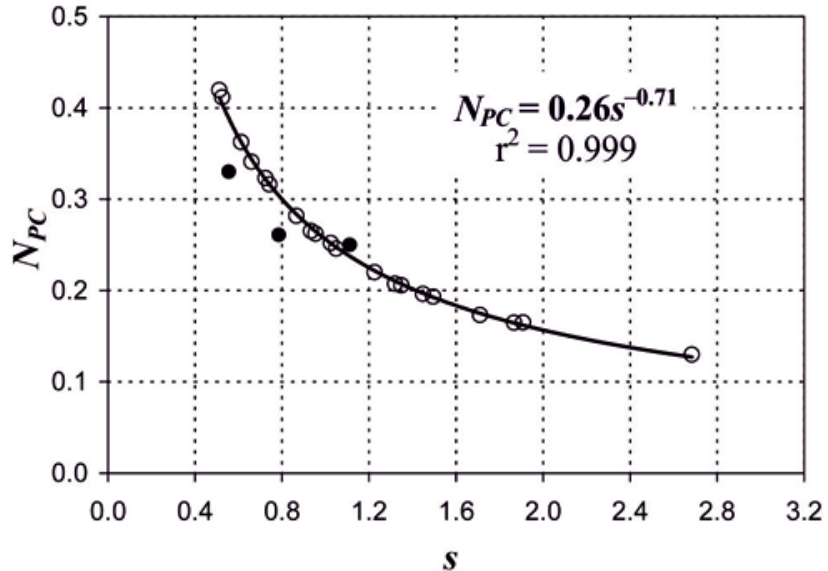

(b) concrete: $\sigma_{\mathrm{c}}=40 \mathrm{MPa}, \mathrm{G}_{\mathrm{C}}=30 \mathrm{~N} / \mathrm{mm}, \sigma_{\mathrm{u}}=4 \mathrm{MPa}, \mathrm{G}_{\mathrm{F}}=0.08 \mathrm{~N} / \mathrm{mm}$. The steel yielding strength has been set equal to $400 \mathrm{MPa}$. With reference to the typical moment versus rotation curve obtained by the application of the proposed algorithm and shown in Figure 12a, the plastic component of the total rotation can be obtained as the difference between the rotation beyond which the moment starts descending rapidly and the rotation corresponding to the reinforcement yielding. It is worth noting that the softening or even snap-back branches at the end of the plastic plateau are usually due to concrete crushing, and can be captured only if the crushing zone extension is assumed to govern the loading process.

The results of the parametric analysis can be summarized in a plastic rotation, $\vartheta_{\mathrm{PL}}$, versus relative neutral axis position, $x / d$, diagram. This is also consistent with the practical prescriptions of the Eurocode 2 [6]. The numerical results referred to different beam depths are compared in Figure 12b with the curve provided by Eurocode 2 for high ductility steel and concrete compressive strength less than or equal to $50 \mathrm{MPa}$. Beams with a depth equal to $0.2 \mathrm{~m}$ have a rotational capacity greater than that suggested by the code. On the other hand, by increasing the beam depth up to $0.8 \mathrm{~m}$, the rotations provided by the code appear to be not conservative. It is worth noting that the numerical results for $h=0.4 \mathrm{~m}$ are however in good agreement with the curve provided by the code, which represents the $5 \%$-fractile of the plastic rotations of beams or slabs with depth of about $0.3 \mathrm{~m}$ (see Eligehausen et al. [30] for more details).

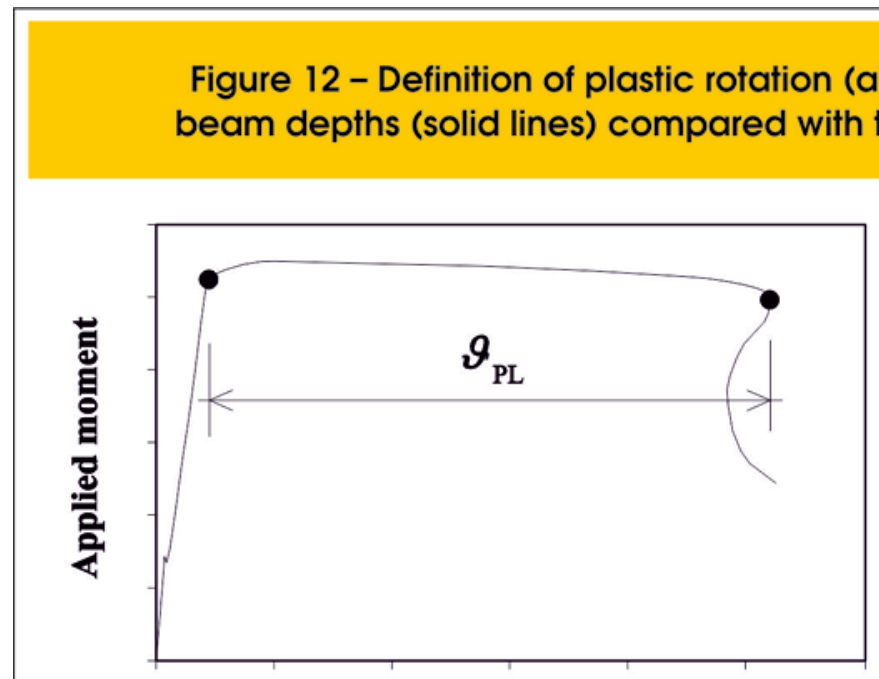

Rotation

(a)

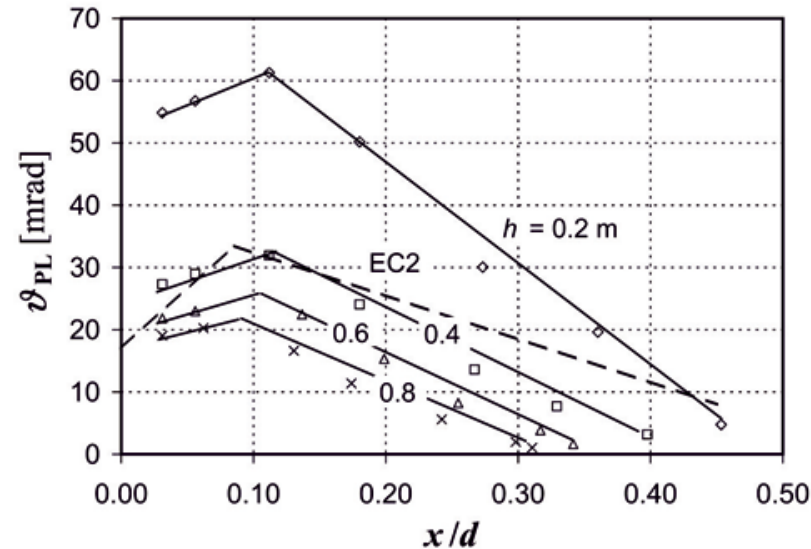

(b) 
In order to investigate the existence of limits to the prescriptions of the $\mathrm{ACl}$ Building Code due to size-scale effects, the allowable degree of moment redistribution is determined from the available rotation capacity of plastic hinges necessary to develop a collapse mechanism in a statically indeterminate RC member. Two limit conditions from the point of view of the structural system are considered: continuous beam over three supports, and fixed-end two-span continuous beam. In both cases, a uniformly distributed load $q$ is applied. The elastic bending moment acting at the central support is given by:

$$
M=k q L^{2}
$$

where $k$ is equal to 0.125 for the continuous beam over three supports, and to 0.083 for the fixed-end two-span continuous beam. When the ultimate resistant moment $M_{\mathrm{PL}}$ is reached, a plastic hinge starts to develop by the central support. At this point, each span is able to bear a load increment, $\Delta q$, according to the scheme of simply supported beam $\left(M=\Delta q L^{2} / 8\right)$. From the kinematical point of view, and ignoring the resistant moment capacity of the mid-span cross-section, $\Delta q$ is limited by the plastic rotation capacity of the plastic hinge according to the following expression:

$$
\Delta q=\frac{24 E_{c} I^{*}}{L^{3}} \frac{\vartheta_{\mathrm{PL}}}{2}
$$

where $L$ is the beam span, $E_{\mathrm{c}}$ is the concrete elastic modulus, and $l^{*}$ is a moment of inertia which takes into account the variation in the flexural stiffness along the beam span according to the study performed by Cosenza et al. [31]. The admissible rotation $\vartheta_{\mathrm{PL}}$, obtained from the diagrams in Figure $12 \mathrm{~b}$ as a function of $x / d$ and of the beam depth is divided by two due to the symmetry of the problem. In this way it is possible to evaluate the moment redistribution factor as follows:

$$
M_{r e d, \%}=\left(1-\frac{M_{P L}}{M_{E L}}\right) 100
$$

where $M_{E L}$ is the elastic bending moment at the central support due to the effect of the maximum load carried out by the beam, $(q+\Delta q)$, evaluated in the hypothesis of uncracked sections.

The admissible redistribution is shown in Figure 13a as a function of the coefficient of resistance defined by $\mathrm{ACl}$ Building Code for a concrete compressive strength $\sigma_{\mathrm{c}}=40 \mathrm{MPa}$, a slenderness $\mathrm{L} / \mathrm{d}$ $=30-d$ is the effective beam depth-, and different beam depths. In this diagram, only the fixed-end two-span continuous beam is analyzed. Consistently with the size-scale effects on the rotational capacity evidenced in Figure 12b, the allowable moment redistribution is now a decreasing function of the beam depth. It is worth noting that the curve provided by the $\mathrm{ACl}$ Building Code for $\sigma_{\mathrm{c}}=$ $41 \mathrm{MPa}$ (6000 psi in Figure 3), becomes unconservative for beam depths higher than approximately $1.0 \mathrm{~m}$. Finally, the effect of the constraints is investigated in Figure $13 \mathrm{~b}$ for $\sigma_{\mathrm{c}}=40 \mathrm{MPa}, h=2.0 \mathrm{~m}$, and $L / d=30$. The redistribution capacity of a fixed-end two-span continuous beam is slightly lower than that of a continuous beam over three supports.

\section{Discussion and conclusions}

In the present paper, a numerical method able to describe the nonlinear behavior of RC members during both tensile fracturing and compression crushing has been presented. With the proposed algorithm, based on nonlinear fracture mechanics concepts, it is possible to completely capture the moment vs. rotation response of all the intermediate situations ranging from pure concrete to over-reinforced concrete beams under monotonic loadings. In particular, the problem of minimum reinforcement and the behavior of plastic hinges have been analyzed in order to highlight the limits of the code prescriptions and provide new easy-to-use design formulae and/or diagrams.

According to the new proposal expressed by Eq. (13), the minimum reinforcement amount, $\rho_{\min }$, is an increasing function of the concrete tensile strength and toughness, whereas it decreases as the steel yielding strength and the beam depth increase. As regards the size-scale effects, the presence of cohesive closing stresses determines a variation in $\rho_{\min }$ with the beam size described by the power $h^{-0.15}$. With reference to the existing code provisions, the proposed formula permits to save steel reinforcement in the case of large structures.

As far as the plastic rotation capacity is concerned, the obtained numerical results summarized in Figure 12b show that $\vartheta_{P L}$ is not only dependent on the neutral axis position. This assumption, in fact, leads to unconservative predictions for deep beams. On the other hand, the allowable moment redistribution vs. coefficient of resistance curves provided by the $\mathrm{ACI}$ Building Code are in general conservative for standard beam depths, due to the fact that they involve a safety factor with respect to the effects of slenderness and steel yielding strength [12]. However, the comparison with the numerical results in Figure 13 show that they become unconservative for very deep beams. In both cases, in order to improve the code provisions, the effect of the structural dimension should be explicitly taken into account by considering different design curves as, for instance, those proposed in Figures $12 \mathrm{~b}$ and 13 .

Finally, as a result of the comprehensive investigation proposed in this paper, the conditions for the structural design of RC elements exhibiting ductile response are highlighted. From a qualitative point of view, the decrease in one parameter among $h, \rho$, and $\sigma_{\mathrm{y}}$, or the increase in $\sigma_{\mathrm{c}}$ or $K_{l c}$, all the other parameters being kept constant, determines a transition from ductile response to unstable tensile crack propagation, as represented in Figure 1. On the other hand, the increase in $h$, or $\rho$, or $\sigma_{y}$, or the decrease in $\sigma_{c}$ or $K_{I C}$, all the other parameters being kept constant, produces a transition towards crushing failure without steel yielding (see Figure 1).

\section{Acknowledgements}

The financial supports provided by the Ministry of University and Scientific Research (MIUR) to the project "Advanced applications of Fracture Mechanics for the study of integrity and durability of materials and structures" and by the Regione Piemonte to the 


\section{Figure 13 - Predicted admissible moment redistribution vs. coefficient of resistance (solid lines) for different beam depths (a) and different structural systems (b), compared with the $\mathrm{ACl}$ prescription (dashed line)}

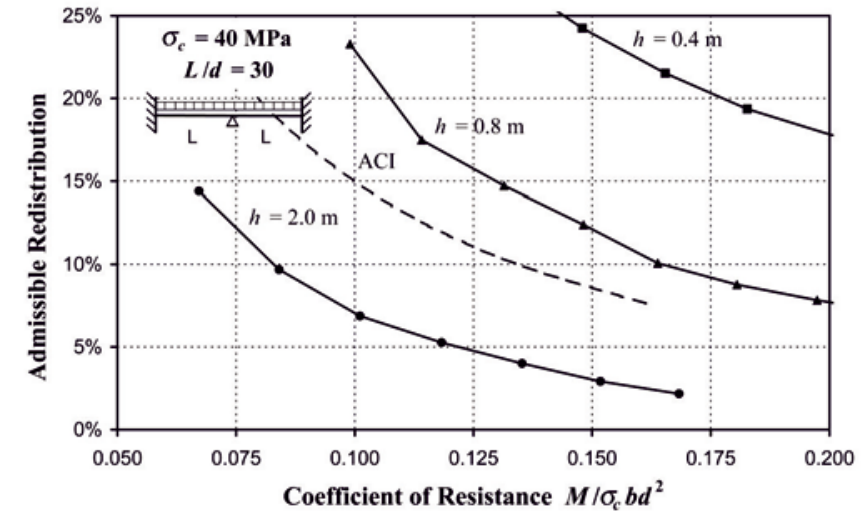

(a)

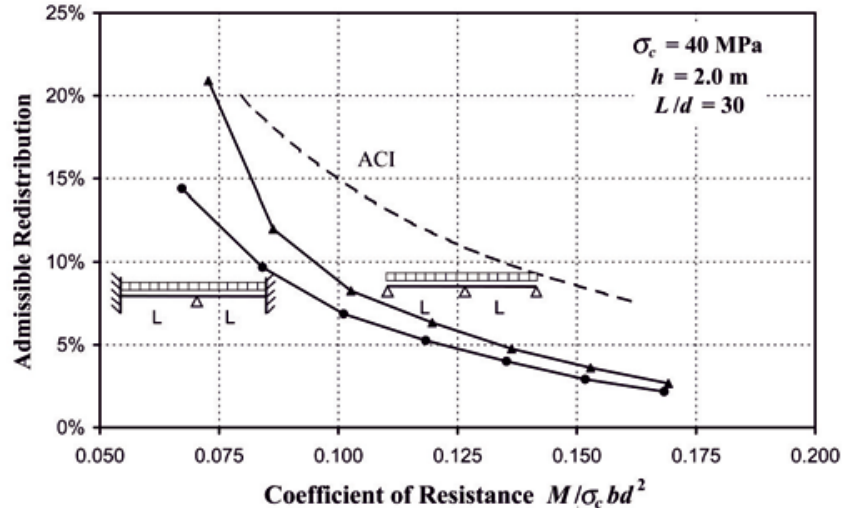

(b)
RE-FRESCOS project: "Preservation, safeguard and valorisation of masonry decorations in the architectural historical heritage of Piedmont", are gratefully acknowledged.

\section{References}

[01] Corley, G.W. Rotational capacity of reinforced concrete beams. Journal of Structural Division, v. 92, pp.121-146, 1966.

[02] Macchi, G. Limit-states design of statically indeterminate structures composed of linear members. Costruzioni in Cemento Armato, Studi e Rendiconti, v. 6, pp.151-191, 1969.

[03] Macchi, G. Elastic distribution of moments on continuous beams. International Symposium on the Flexural Mechanics of Reinforced Concrete, ASCE, $\mathrm{ACl}$, Miami, 1964.

[04] Norwegian Standard. NS 3473 Concrete Structures, Design Rules. Norwegian Council for Building Standardization, Oslo, Norway, 1989.

[05] Comité Euro-International du Béton. CEB-FIP Model Code 1990. Thomas Telford Ltd, Lausanne, Bulletin, n. 213/214, 1993.

[06] CEN TC/250 2004. Eurocode 2: Design of Concrete Structures, Part 1-1: General Rules and Rules for Buildings. Brussels, par. 5.6.

[07] Comité Euro-International du Béton. Bulletin d'Information, n. 30, 1961.

[08] Eligehausen, R., Langer, P. Rotation capacity of plastic hinges and allowable moment redistribution. CEB Bulletin d'Information, n. 175, pp.I 7.9 - I 7.27, 1987.

[09] Bigaj, A.J., Walraven, J.C. Size effect on rotational capacity of plastic hinges in reinforced concrete beams. CEB Bulletin d'Information, n. 218, pp.7-23, 1993.

[10] Bosco, C., Debernardi, P.G. Influence of some basic parameters on the plastic rotation of reinforced concrete elements. CEB Bulletin d'Information, n. 218, pp.25-44, 1993.

[11] ACl-318. Building Code Requirements for Reinforced Concrete", Detroit, 2005

[12] Mast, R.F. Unified design provisions for reinforced and prestressed concrete flexural and compression members. ACI Structural Journal, v. 89, n. 2, pp.185-199, 1992.

[13] Hillerborg, A., Modeer, M., Petersson, P.E. Analysis of crack formation and crack growth in concrete by means of fracture mechanics and finite elements. Cement and Concrete Research, v. 6, pp.773-782, 1976.

[14] Hillerborg, A. Fracture mechanics concepts applied to moment capacity and rotational capacity of reinforced concrete beams. Engineering Fracture Mechanics, v. 35, pp.233-240, 1990.

[15] Carpinteri, A., Corrado, M., Paggi, M., Mancini, G. Cohesive versus overlapping crack model for a size effect analysis of RC elements in bending. In: Proceedings of FraMCoS-6, Catania, Italy, 2007, Taylor \& Francis, London, v. 2, pp.655-663, 2007.

[16] Carpinteri, A., Corrado, M., Paggi, M., Mancini, G. New model for the analysis of size-scale effects on the ductility of reinforced concrete elements in bending. ASCE Journal of Engineering Mechanics, v. 135, pp.221-229, 2009.

[17] Carpinteri, A., Corrado, M., Mancini, G., Paggi M. Size-scale effects on plastic rotational capacity of RC beams. ACI Structural Journal, v. 106, n. 6 , pp.887-896, 2009.

[18] Carpinteri, A., Corrado, M., Paggi, M. An analytical model based on strain localization for the study of size-scale and slenderness effects in uniaxial compression tests. Strain. DOI: 10.1111/j. 1475-1305.2009.00715.x 
[19] Carpinteri, A. Interpretation of the Griffith instability as a bifurcation of the global equilibrium.

In: Application of Fracture Mechanics to Cementitious Composites, Martinus Nijhoff Publishers, Dordrecht, pp.287-316, 1985.

[20] Carpinteri, A. Size effects on strength, toughness, and ductility. ASCE Journal of Engineering Mechanics, v. 115, n. 7, pp.1375-1392, 1989.

[21] van Mier, J.G.M. Strain-softening of Concrete under Multiaxial Loading Conditions. PhD Thesis, Eindhoven, University of Technology, 1984.

[22] Jansen, D.C., Shah, S.P. Effect of length on compressive strain softening of concrete. ASCE Journal of Engineering Mechanics, v. 123, pp.25-35, 1997.

[23] Suzuki, M., Akiyama, M., Matsuzaki, H., Dang, T.H. Concentric loading test of RC columns with normal- and high-strength materials and averaged stress-strain model for confined concrete considering compressive fracture energy. In: Proceedings of the 2nd fib Congress, Naples, Italy, 2006, CD-ROM.

[24] Ruiz, G., Elices, M., Planas, J. Size effects and bond-slip dependence of lightly reinforced concrete beams. In: Minimum reinforcement in concrete members, A. Carpinteri, ed., Elsevier Science Ltd. Oxford, U.K., pp.127-180, 1999.

[25] Bosco, C., Carpinteri, A., Debernardi, P.G. Minimum reinforcement in high-strength concrete. Journal of Structural Engineering (ASCE), v. 116, n. 2, pp.427-437, 1990.

[26] Buckingham, E. Model experiments and the form of empirical equations. ASME Transaction, v. 37, pp.263-296, 1915.

[27] Carpinteri, A. Static and energetic fracture parameters for rocks and concretes. Materials \& Structures, v. 14, pp.151-162, 1981.

[28] Carpinteri, A. Sensitivity and stability of progressive cracking in plain and reinforced cement composites. International Journal of Cement Composites and Lightweight Concrete, v. 4, n. 1, pp.47-56, 1982.

[29] Carpinteri, A Stability of fracturing process in R.C. beams. ASCE Journal of Structural Engineering, v. 110, n. 3, pp. 544-558, 1984.

[30] Eligehausen, R., Fabritius, E., Li, L., Zhao, R. An analysis of rotation capacity tests. CEB Bulletin d'Information, n. 218, pp.251-273, 1993.

[31] Cosenza, E., Greco, C., Pecce, M. Nonlinear design of reinforced concrete continuous beams. Structural Engineering International, v. 1/91, pp.19-27, 1991. 